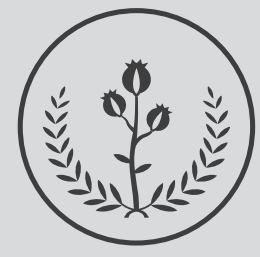

FUCS

\title{
Meningitis aséptica secundaria a la administración de inmunoglobulina
}

Pedro David Vargas MD

Malory Alexandra Moreno $\mathbf{M D}^{\mathrm{a}}$

Aseptic meningitis following immunoglobulin therapy

a Pediatría. Fundación Universitaria de Ciencias de la Salud. Bogotá DC, Colombia.

\section{R E S U M E N}

Introducción: la meningitis aséptica es una entidad infrecuente y multifactorial, siendo raros los efectos secundarios a la administración de inmunoglobulina. Objetivo: reportar el caso de una paciente hospitalizada en el servicio de pediatría en un hospital de Bogotá. Discusión: las principales causas de la entidad son virales. Aunque el uso de inmunoglobulina en pediatría es seguro, uno de sus efectos adversos menos comunes es la meningitis aséptica. Están descritas las posibles teorías fisiopatológicas que podrían explicar su desenlace. Conclusión: la meningitis aséptica puede corresponder a un efecto secundario al uso de inmunoglobulina en pediatría.

Palabras clave: meningitis aséptica, meningitis aséptica inducida por medicamentos, enfermedad de Kawasaki, inmunoglobulina IV, efectos adversos.

(C) 2021 Fundación Universitaria de Ciencias de la Salud - FUCS. Este es un artículo Open Access bajo la licencia CC BY-NC-ND (http://creativecommons.org/licenses/by-nc-nd/4.0/).

\section{ABSTRACT}

Introduction: aseptic meningitis is a rare and multifactorial entity and side effects of immunoglobulin therapy are rare. Objective: to report the case of a female patient hospitalized in the pediatrics service in a hospital in Bogotá. Discussion: the most common cause of aseptic meningitis is viral infection. Although the use of immunoglobulin therapy in pediatric patients is safe, one of its less common adverse effects is aseptic meningitis. The pathophysiological theories that could explain its outcome have been described. Conclusion: aseptic meningitis may be a side effect to the use of immunoglobulin in pediatric practice.

Key words: aseptic meningitis, aseptic meningitis induced by drugs, Kawasaki disease, immunoglobulin IV, adverse effects.

(C) 2021 Fundación Universitaria de Ciencias de la Salud - FUCS. This is an open access article under the CC BY-NC-ND license ( ñhttp://creativecommons.org/licenses/by-nc-nd/4.0/).

INFORMACIÓN DEL ARTÍCULO

Historia del artículo:

Fecha recibido: febrero 28 de 2019

Fecha aceptado: junio 30 de 2020
Autor para correspondencia. Dr. Pedro David Vargas pdvargas@fucsalud.edu.co
DOI

10.31260/RepertMedCir.01217372.899 
INTRODUCCIÓN

La meningitis aséptica es una entidad poco frecuente de causa multifactorial. Se describen causas infecciosas y no infecciosas, dentro de las últimas están las secundarias a medicamentos como inmunomoduladores, antiinflamatorios y antibióticos entre otros ${ }^{1}$, siendo una de las menos frecuentes el uso de inmunoglobulina (lg IV). Existen algunos reportes de caso describiendo este efecto, pero se desconoce la incidencia y el mecanismo causal. ${ }^{2}$

\section{PRESENTACIÓN DEL CASO}

Escolar de 7 años, femenina, procedente de Bogotá con antecedente reciente de enfermedad de Kawasaki típica con criterios clínicos y ecocardiográficos (dilatación de arteria coronaria derecha), tratada con una dosis de inmunoglobulina $2 \mathrm{~g} / \mathrm{k}$, y ácido acetil salicílico $90 \mathrm{mg} / \mathrm{k} /$ día, por 5 días, y después anti agregación $2 \mathrm{mg} / \mathrm{k} /$ día. 15 días después del manejo inicial llegó a la consulta de cardiología pediátrica del servicio de urgencias por cuadro de cefalea holocraneana de intensidad moderada, además de persistencia de conjuntivitis bilateral no supurativa. En estudios complementarios se documentaron aumento de reactantes de fase aguda, aumento de la dilatación coronaria derecha y dilatación de la arteria circunfleja derecha. Valorada por el servicio de reumatología pediátrica consideraron que se trataba de una recaída de la enfermedad de Kawasaki y como hallazgo asociado seroconversión de IgG e igM para Epstein Barr, secundaria a la administración de inmunoglobulina. Considerando que la recaída es poco usual, se iniciaron estudios para descartar otras causas vasculíticas que explicaran el cuadro clínico.

Al examen físico se encontró alteración del sexto par craneano derecho, además de marcada congestión conjuntival bilateral no supurativa. Durante la hospitalización se documentó persistencia del aumento de los reactantes de fase aguda, razón por la cual se aplicó una segunda dosis de inmunoglobulina y ASA con las mismas dosis mencionadas. Debido a que los reactantes de fase aguda persistían elevados y ante la sospecha de compromiso vascular del VI par craneal, fue valorada por neuropediatría. La resonancia magnética cerebral y de pares craneales no mostró hallazgos relevantes, en el servicio de oftalmología pediátrica evidenciaron papiledema bilateral. La punción lumbar reveló leucorraquia sin presencia de gérmenes sugestiva de meningitis aséptica, la cual se consideró secundaria a la administración de inmunoglobulina. La administración de pulsos de metilprednisolona cursó con mejoría clínica y paraclínica. Se dio egreso con seguimiento por neurología, cardiología y reumatología pediátrica.

\section{DISCUSIÓN}

La meningitis aséptica (MA) es un síndrome meníngeo caracterizado por fiebre $(86 \%)$, cefalea $(79 \%)$, meningismo (70\%), fotofobia, náuseas y vómito, alteración del nivel de conciencia $(50 \%)$ y erupción cutánea, asociado con un líquido cefalorraquídeo LCR que evidencia leuocorraquia sin microorganismos bacterianos o fúngicos. La entidad es benigna y autolimitada en la mayoría de casos, su etiología es casi siempre viral $(95 \%)$ en la que los agentes causales más destacados son enterovirus y virus de herpes simple. ${ }^{3}$ Las causas no virales son raras entre las que se han visto relacionadas entidades como leucemia, lupus eritematoso sistémico y enfermedad de Kawasaki, además de medicamentos entre los cuales se han descrito AINES, Ig IV, antibióticos, anticuerpos monoclonales, anticonvulsivantes (lamotrigina y carbamazepina), entre otros. ${ }^{1}$

La MA asociada con medicamentos se considera un efecto adverso raro y grave, secundario al tratamiento con inmunoglobulina, producto sanguíneo de anticuerpos polivalentes de inmunoglobulina G proveniente de miles de donantes de plasma. Posee un mecanismo inmunomodulador que no se ha descrito con claridad, pero se han postulado teorías que sugieren inhibición de los macrófagos en el tejido reticuloendotelial a través del receptor específico para anticuerpos llamados $\mathrm{Fc}^{3}$, además de supresión de citoquinas, captación de complemento e inducción de apoptosis, por lo que se usa en gran variedad de enfermedades que incluyen inmunodeficiencias, enfermedades inflamatorias y autoinmunes como la enfermedad de Kawasaki; los efectos adversos se presentan entre 1 y $15 \%$, y suelen ser leves (cefalea, fiebre, mialgias, náuseas y vómito).

La MA secundaria al uso de inmunoglobulina tiene una incidencia estimada de $0.067 \%$. El primer caso descrito fue en 1988 en una paciente de 2 años con púrpura trombocitopenica idiopática que desarrolló MA siete días después de recibir tratamiento con Ig IV; la clínica suele iniciarse entre 48 horas y 7 días después de aplicar la $\lg$ G IV. Dentro de los mecanismos fisiopatológicos se han postulado cuatro hipótesis: a) efecto tóxico directo; b) reacción de hipersensibilidad a medicamentos (activación del complemento o por interacción de la inmunoglobulina con determinantes antigénicos en los vasos sanguíneos); c) reacción inmune alogénica y d) reacción de hipersensibilidad secundaria a la liberación de citoquinas pro- inflamatorias 1 .

En el estudio realizado por Berg se identificó mayor incidencia de MA secundaria a la aplicación de inmunoglobulina en pacientes del sexo femenino, con una relación $4 / 1 .{ }^{2}$ Bharath y col. en un estudio realizado durante 6 años, reportaron incidencia de MA secundaria a inmunoglobulina de $0.6 \%$, siendo significativamente mórbida con complicaciones similares a la meningitis causada por microorganismos. ${ }^{4}$ 
Existen reportes de caso en poblaciones adulta y pediátrica sobre la instauración de MA secundaria a la administración de inmunoglobulina, la mayoría en tratamiento de púrpura trombocitopénica. Los autores relatan como posibles variables la dosis utilizada, vía de administración y la velocidad de infusión, y sugieren que esta no sea mayor de 6 $\mathrm{g} /$ hora, aunque no hay estudios estadísticos que confirmen esta teoría. ${ }^{5}$

\section{CONCLUSION}

Aunque es un efecto adverso poco frecuente es de suma importancia resaltar que la MA es una de las complicaciones más graves secundarias al uso de la inmunoglobulina. El personal médico debe tener en cuenta esta complicación en los pacientes que requieren dicha terapia.

\section{REFERENCIAS}

1. Yelehe-Okouma M, Czmil-Garon J, Pape E, Petitpain N, Gillet P. Drug-induced aseptic meningitis: a mini-review. Fundam Clin Pharmacol. 2018;32(3):252-260. doi: 10.1111/fcp.12349

2. Berg R, Fuellenhals E. Aseptic meningitis following therapy with immune globulins: a combination of product features and patient characteristics? Transfusion. 2016;56(12):3021-3028. doi: $10.1111 / \operatorname{trf} .13886$

3. Bharath V, Eckert K, Kang M, Chin-Yee IH, Hsia CC. Incidence and natural history of intravenous immunoglobulin-induced aseptic meningitis: A retrospective review at a single tertiary care center. Transfusion. 2015;55(11):2597-605. doi: 10.1111/trf.13200

4. Puy-Núñez A, Dacosta-Balboa M, Cabo-López I, Canneti B, LópezFerreiro A, Rodríguez-Álvarez JR, et al. Meningitis aséptica como complicación del tratamiento con inmunoglobulinas en la miastenia grave. Rev Neurol. 2016;62(10):478-9. doi: 10.33588/ rn.6210.2015492

5. Emiroglu M, Alkan G, Kartal A, Cimen D. Abducens nerve palsy in a girl with incomplete Kawasaki disease. Rheumatol Int. 2016;36(8):1181-1183. doi: 10.1007/s00296-016-3515-2 